\title{
DFT Study on Adsorption of Arsenic by Oxides in Fly Ash
}

\author{
Yang Ling ${ }^{1}$, Jiang $\mathrm{Wu}^{1, *}$, Jianshu $\mathrm{Zou}^{1}$ and Min Zhou ${ }^{1}$ \\ ${ }^{1}$ College of Energy and Mechanical Engineering, Shanghai University of Electric Power, Shanghai 200090, P. R. China
}

\begin{abstract}
Based on density functional theory (DFT), the adsorption properties of arsenic (As) via the five most abundant oxides in fly ash were investigated. It has been proved that the iron oxide $\left(\mathrm{Fe}_{2} \mathrm{O}_{3}\right)$ in fly ash is the effective active component during the adsorption process. This paper verifies the feasibility of using fly ash as the adsorbent to control As pollution in power plants, and also provides some reference for the subsequent experimental research.
\end{abstract}

\section{Introduction}

Coal is the most important energy source in China, which can not be replaced for a long time. With the burning of coal, the corresponding pollutants are generated. Traditional pollutants of coal-fired flue gas, such as nitrogen oxide $\left(\mathrm{NO}_{\mathrm{x}}\right)$, sulfur dioxide $\left(\mathrm{SO}_{2}\right)$ and dust, have been widely studied by scholars [1, 2]. However, there are few researches focus on the trace heavy metal pollutants in coal-fired flue gas. The content is not high, but their emissions into the atmosphere has considerable damage to the ecological environment, and is difficult to control $[3,4]$. At present, studies mainly focus on mercury $(\mathrm{Hg})$, cadmium $(\mathrm{Cd})$, chromium $(\mathrm{Cr})$ and other heavy metals, but relatively few studies on arsenic (As) emission. The As forms in flue gas and its treatment methods are still in the exploration stage.

Adsorption method is a potential way to reduce emission of coal-fired pollutants. It is characterized by the use of some specific adsorbents to adsorb the target pollutants in the flue gas, so as to achieve the purpose of fixing pollutants. He et al. [5] found that chlorine modified activated carbon helps enhance the adsorption of mercury. But its high cost limits the industrial application. In comparison, fly ash, as a by-product of coal combustion, has incomparable advantages. Fly ash is almost cost-free and the production is huge. The effective use of fly ash to remove pollutants from flue gas is beneficial to the recycling of resources, so as to improve the economic benefits of power plants. However, the complex composition of fly ash makes it difficult to study the mechanism of pollutant removal reaction. It is hard to determine which active component of fly ash plays the main role, so it is difficult to further modify fly ash to improve the efficiency of pollutant removal. On the other hand, if the experiment is carried out directly on the site of power plant, the cost must be very high and affects the work of the flue gas treatment system of the power plant. If studied in a laboratory, the preparation of simulated smoke containing gaseous As requires a large initial investment and a big time cost.
All these factors bring difficulties to the study of As adsorption by fly ash.

The computation based on the density functional theory (DFT) is a popular method in quantum chemistry. It is the method to study the electronic structure of multielectron system, which can effectively simulate the crystal surface of adsorbent and evaluate the adsorption ability. Through DFT calculation, the main active components that adsorb As atom in fly ash can be preliminarily screened out, which can provide certain reference for subsequent laborator-scale research and reduce the time and cost of experimental research. Liu et al. [6] found that the five most abundant oxides in fly ash were: $\mathrm{SiO}_{2}, \mathrm{Al}_{2} \mathrm{O}_{3}, \mathrm{Fe}_{2} \mathrm{O}_{3}, \mathrm{CaO}$ and $\mathrm{MgO}$. In this work, the five most abundant oxides in fly ash are used as potential adsorbents for As adsorption. Each oxide was cleaved into a representative crystal surface, and the As atoms were placed on some potential adsorption points. The stability of adsorption was evaluated via the adsorption energy and the active components of fly ash were confirmed. This paper verified the feasibility of using fly ash as the adsorbent to removal As pollutant, while it also provides some reference for subsequent experimental research.

\section{Calculation method}

The Density Functional Theory (DFT) calculation were taken on the Cambridge Serial Total Energy Package (CASTEP) codes. The exchange and correlation effects were described by the Perdew-Burke-Ernzerhof (PBE) functional within generalized gradient approximation (GGA). An energy cutoff was set as $381.0 \mathrm{eV}$ and the kpoint set as $1 * 1 * 1$. The convergence criteria were as follows: maximal force on the atoms $0.1 \mathrm{eV} / \AA$, maximal stress on the atoms $0.2 \mathrm{GPa}$, maximal atomic displacement $0.005 \AA$, and maximal energy $5.0 \times 10^{-5}$ eV/atom. The absorption energy is calculated by the following formula:

$$
\mathrm{E}_{\mathrm{ad}}=\mathrm{E}(\mathrm{AB})-\mathrm{E}(\mathrm{A})-\mathrm{E}(\mathrm{B})
$$

\footnotetext{
* Corresponding author: wjcfd2002@163.com
} 
where $E_{a d}$ represents the absorption energy. $E(A B)$ is the total energy of $\mathrm{B}$ molecule adsorbed by A molecular surface. $E(A)$ and $E(B)$ represent the total energy of isolated $\mathrm{A}$ and $\mathrm{B}$ molecule, respectively. Commonly, a negative adsorption energy indicates that the structure is spontaneous. And a lower adsorption energy indicates that the adsorption configuration is more stable.

\section{Results and discussion}

\section{$3.1 \mathrm{SiO}_{2}$}

The $\mathrm{\beta}-\mathrm{SiO}_{2}$ model is used in this work. After geometric optimization, the $\mathrm{SiO}_{2}$ bulk is cleaved into the (100) surface. To mitigate the effects of adjacent adsorbed atoms, a supercell size with $2 * 2 * 1$ is used. The vacuum layer is set as $15 \AA$ to reduce the impact of the neighbouring layers. As shown in Fig. 1, the surface of $\mathrm{SiO}_{2}(110)$ has four silicon atoms in its outermost layer, and forming a rectangle between them. It is initially speculated that the $\mathrm{SiO}_{2}(100)$ surface consists of five highly symmetrical positions, which may be the potential adsorption points: Si top site $\left(\mathrm{Si}_{\mathrm{T}}\right)$, $\mathrm{O}$ top site $\left(\mathrm{O}_{\mathrm{T}}\right)$, long bridge site (LB), short bridge site (SB) and hollow site $(\mathrm{H})$. The As atoms are placed on the above five locations for geometric optimization, and the final configuration is obtained as shown in Fig. 2, while the corresponding adsorption energy is also marked in the diagram. (a)

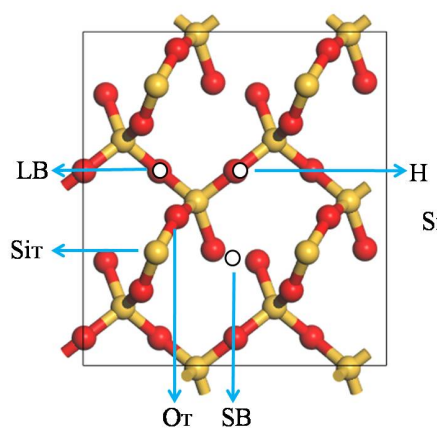

(b)

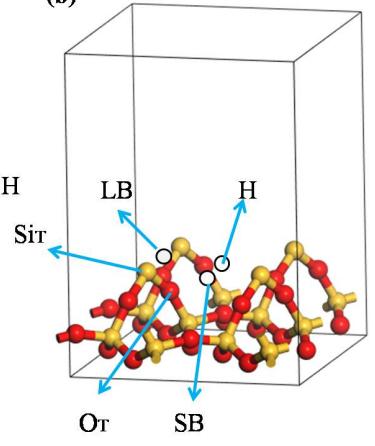

Fig. 1. The geometry optimized structure and potential adsorption sites of the $\mathrm{SiO}_{2}(100)$ surface: (a) top view from (100) facet; (b) 3D view.

From Fig. 2a, when As atom starts on $\mathrm{Si}_{\mathrm{T}}$ or $\mathrm{O}_{\mathrm{T}}$ site, the final structure is on the $\mathrm{Si}_{\mathrm{T}}$ site, and the adsorption energy is $-3.930 \mathrm{eV}$. The distance between $\mathrm{As}$ and $\mathrm{Si}_{\mathrm{T}}$ atom is $2.170 \AA$. When the initial structure is on the LB site, the As atom has shifted a lot after the geometry optimization and it's close to the $\mathrm{Si}_{\mathrm{T}}$ atom (Fig. 2b). The adsorption energy is $-3.927 \mathrm{eV}$ and the $\mathrm{As}^{-\mathrm{Si}_{\mathrm{T}}}$ distance is $2.226 \AA$. While when As atom starts at $\mathrm{SB}$ or $\mathrm{H}$ site, it ends up at SB site with the adsorption energy of -4.068 $\mathrm{eV}$ (Fig. 2c). The As atom is preferentially adsorbed at short bridge position, followed by Si top position.

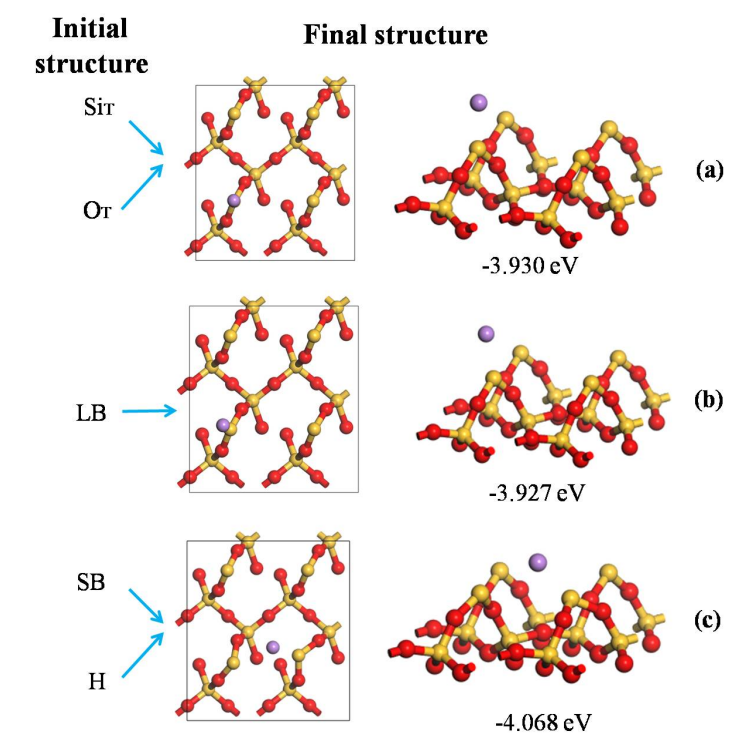

Fig. 2. The adsorption structures of As atoms at different adsorption sites.

\section{$3.2 \mathrm{Al}_{2} \mathrm{O}_{3}$}

$\mathrm{Al}_{2} \mathrm{O}_{3}$ is also an important part of fly ash, so it is necessary to discuss its adsorption property of As. After geometric optimization, the $\mathrm{Al}_{2} \mathrm{O}_{3}$ bulk is cleaved and exposed to the (110) surface. The supercell size is $2 * 2 * 1$ and the vacuum layer is $15 \AA$. As shown in Fig. 3, the representative potential surface adsorption sites are selected as $\mathrm{Al}$ top site $\left(\mathrm{Al}_{\mathrm{T}}\right)$, $\mathrm{O}$ top site $\left(\mathrm{O}_{\mathrm{T}}\right)$ and hollow site $(\mathrm{H})$. The As atoms are placed on these three sites for geometric optimization, and the final structures are shown in Fig. 4. The corresponding adsorption energy is also marked.
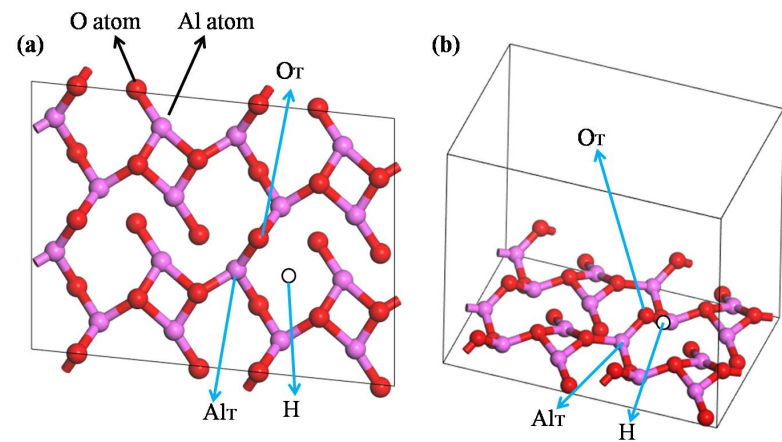

Fig. 3. The geometry optimized structure and potential adsorption sites of the $\mathrm{Al}_{2} \mathrm{O}_{3}(110)$ surface: (a) top view from (110) facet; (b) 3D view.

From Fig. 4a, when putting As on the $\mathrm{Al}_{\mathrm{T}}$ site, after optimization the As atom deviates from $\mathrm{Al}_{\mathrm{T}}$ site and advances in the direction of $\mathrm{O}_{\mathrm{T}}$ site. The $\mathrm{As}-\mathrm{Al}_{\mathrm{T}}$ distance is $2.948 \AA$ and the $A s-O_{\mathrm{T}}$ distance is $1.993 \AA$. The adsorption energy is $-2.295 \mathrm{eV}$ in this case. While when the initial structure of As absorption is on the $\mathrm{O}_{\mathrm{T}}$ site, the final structure is still on $\mathrm{O}_{\mathrm{T}}$ site (Fig. 4b). The distance between $\mathrm{As}$ and $\mathrm{O}_{\mathrm{T}}$ atoms is $1.945 \AA$ and the adsorption energy is $-2.432 \mathrm{eV}$. Nevertheless, the hollow site shows a relatively strong adsorption capacity for As atom which adsorption energy is $-2.704 \mathrm{eV}$ (Fig. 4c). 


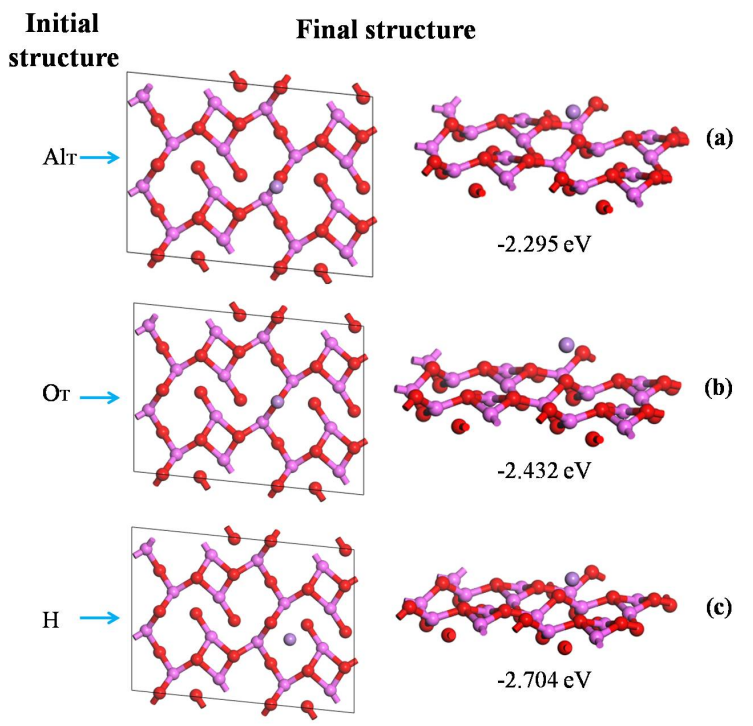

Fig. 4. The adsorption structures of As atoms at different adsorption sites.

\section{$3.3 \mathrm{Fe}_{2} \mathrm{O}_{3}$}

The $\mathrm{Fe}_{2} \mathrm{O}_{3}$ is a common metal oxide in fly ash and is also an important catalyst with many applications. The $\mathrm{Fe}_{2} \mathrm{O}_{3}(100)$ plane is selected as a representative surface in this work. The supercell size is $2 * 1 * 1$ and the vacuum layer is $15 \AA$. As shown in Fig. 5, the representative potential surface adsorption sites are selected as Fe top site $\left(\mathrm{Fe}_{\mathrm{T}}\right)$, $\mathrm{O}$ top site $\left(\mathrm{O}_{\mathrm{T}}\right)$ and hollow site $(\mathrm{H})$. The As atoms are placed on the above sites and the final structures are shown in Fig. 6, while the corresponding adsorption energy is also given.
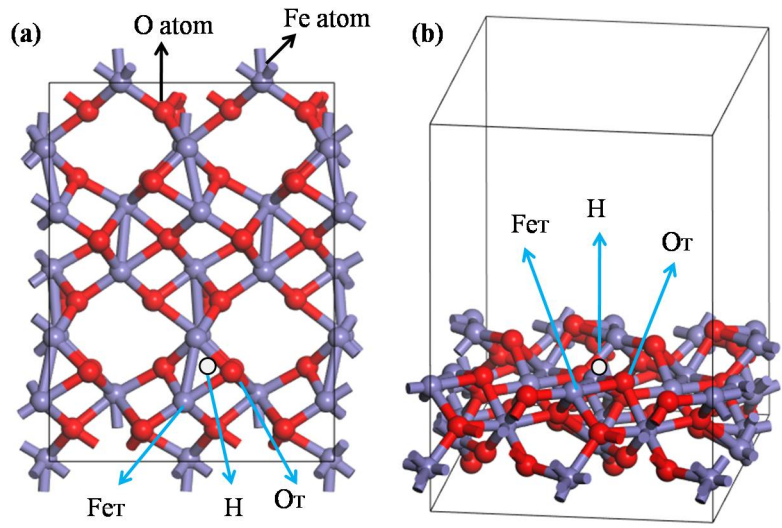

Fig. 5. The geometry optimized structure and potential adsorption sites of the $\mathrm{Fe}_{2} \mathrm{O}_{3}(100)$ surface: (a) top view from (100) facet; (b) 3D view.

From Fig. 6a, the $\mathrm{Fe}_{\mathrm{T}}$ site can adsorb As atom stably, that has a adsorption energy of $-4.614 \mathrm{eV}$ with the As$\mathrm{Fe}_{\mathrm{T}}$ distance of $2.089 \AA$. When As atom is beginning at $\mathrm{O}_{\mathrm{T}}$ or hollow site, the final position is close to the hollow site with the adsorption energy of $-13.860 \mathrm{eV}$, which is the lowest within the five oxides (Fig. 6b). The As atom attaches first to hollow site, followed by $\mathrm{Fe}_{\mathrm{T}}$ site. The hollow site in $\mathrm{Fe}_{2} \mathrm{O}_{3}(100)$ has a strong adsorption ability of As atom.

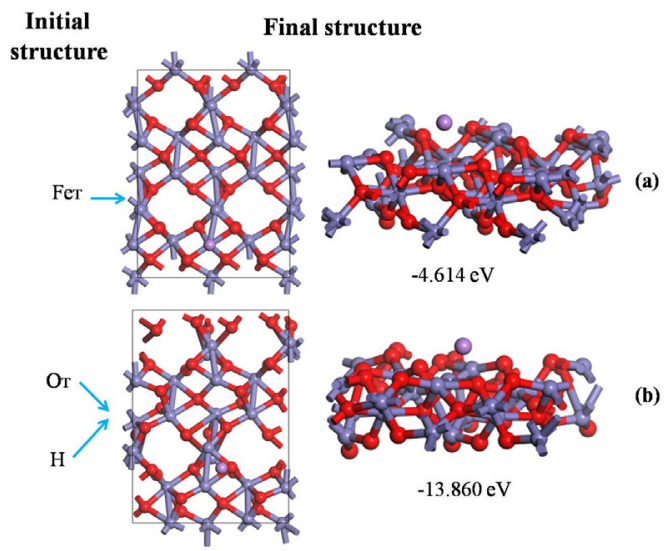

Fig. 6. The adsorption structures of As atoms at different adsorption sites.

\section{$3.4 \mathrm{CaO}$}

$\mathrm{CaO}$, which is less abundant in fly ash, is also studied the adsorption property of As [7]. Fig. 7 shows the (001) surface of $\mathrm{CaO}$ with the supercell size of $2 * 1 * 1$ and the vacuum layer of $15 \AA$. Three highly symmetrical positions are selected as the potential adsorption sites: Ca top site $\left(\mathrm{Ca}_{\mathrm{T}}\right)$, $\mathrm{O}$ top site $\left(\mathrm{O}_{\mathrm{T}}\right)$ and hollow site $(\mathrm{H})$. The final structures are shown in Fig. 8.

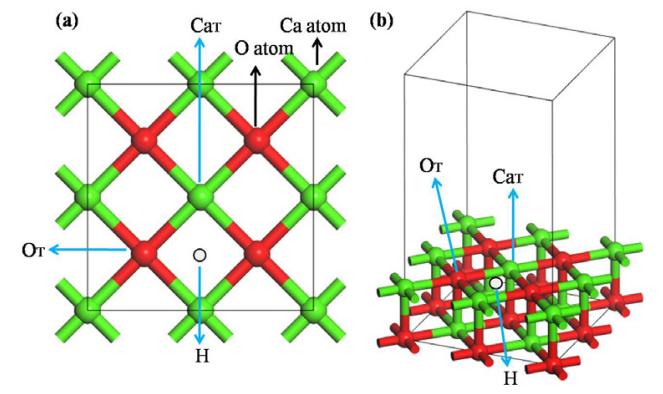

Fig. 7. The geometry optimized structure and potential adsorption sites of the $\mathrm{CaO}(001)$ surface: (a) top view from (001) facet; (b) 3D view.

When As atom starts on $\mathrm{Ca}_{\mathrm{T}}$ site, after geometric optimization it is still on the $\mathrm{Ca}_{\mathrm{T}}$ site (Fig. 8a). The adsorption energy is $-1.281 \mathrm{eV}$ and the $\mathrm{As}^{-\mathrm{Ca}_{\mathrm{T}}}$ distance is $2.921 \AA$. The adsorption energy is relatively high and the adsorption effect is not good. While when As atom starts on $\mathrm{O}_{\mathrm{T}}$ or $\mathrm{H}$ site, after geometric optimization it is on the $\mathrm{O}_{\mathrm{T}}$ site (Fig. 8b). The adsorption energy is -3.851 $\mathrm{eV}$ and the $\mathrm{As}-\mathrm{O}_{\mathrm{T}}$ distance is $1.921 \AA$. The As atom is preferentially adsorbed at $\mathrm{O}_{\mathrm{T}}$ site than $\mathrm{Ca}_{\mathrm{T}}$ site. 


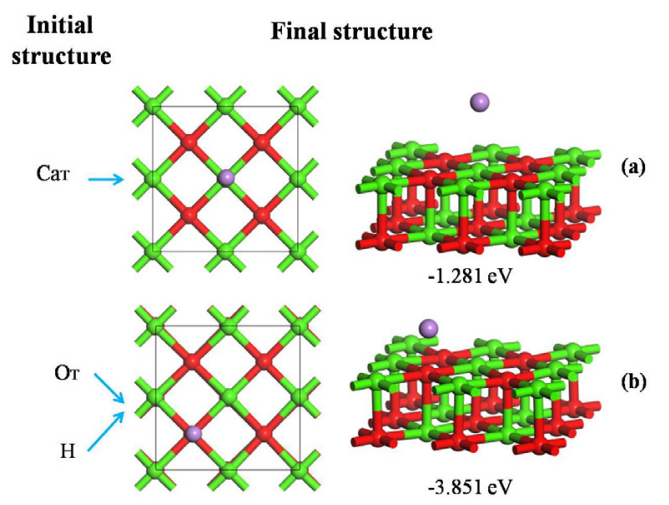

Fig. 8. The adsorption structures of As atoms at different adsorption sites.

\subsection{MgO}

$\mathrm{MgO}$, with low content in fly ash, is also analyzed via the (110) surface (Fig. 9) [8]. The supercell size is $2 * 2 * 1$ and the vacuum layer is $15 \AA$. Four highly symmetrical positions are selected as the potential adsorption sites: the $\mathrm{Mg}$ top site in the upper $\left(\mathrm{Mg}_{\mathrm{T} 1}\right)$, the $\mathrm{Mg}$ top site in the subsurface $\left(\mathrm{Mg}_{\mathrm{T} 2}\right)$, the $\mathrm{O}$ top site in the upper $\left(\mathrm{O}_{\mathrm{T} 1}\right)$ and the $\mathrm{O}$ top site in the subsurface $\left(\mathrm{O}_{\mathrm{T} 2}\right)$. The final structures are shown in Fig. 10, and the corresponding adsorption energy is given.

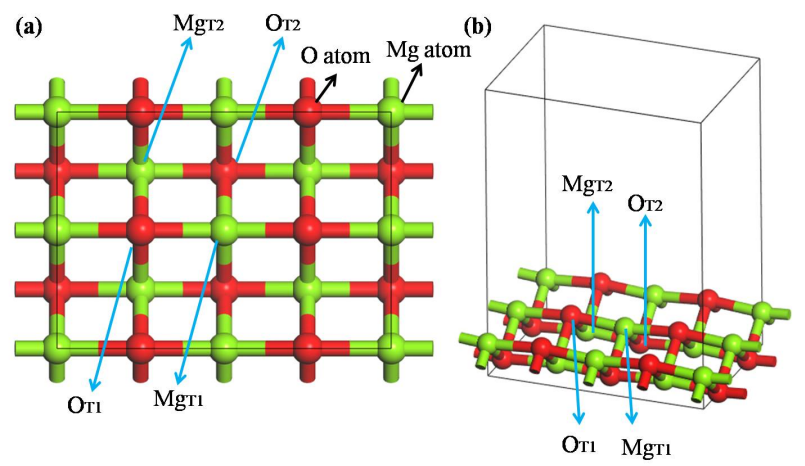

Fig. 9. The geometry optimized structure and potential adsorption sites of the $\mathrm{MgO}(110)$ surface: (a) top view from (110) facet; (b) 3D view.

The As atom can be adsorbed stably at all these four adsorption sites (Fig. 10). The adsorption energy of As atom at $\mathrm{Mg}_{\mathrm{T} 2}$ site is the minimum, reaching $-3.881 \mathrm{eV}$. The adsorption of As at $\mathrm{O}_{\mathrm{T} 1}$ site is also good, with the adsorption energy of $-3.652 \mathrm{eV}$ and the As- $\mathrm{O}_{\mathrm{T} 1}$ distance of $1.931 \AA$. This may be because the surface oxygen atoms in $\mathrm{MgO}$ interact strongly with the As atom. When the As atom is at $\mathrm{Mg}_{\mathrm{T} 2}$ site, the two adjacent oxygen atoms could interact with it, so the adsorption is relatively stable (Fig. 10b).

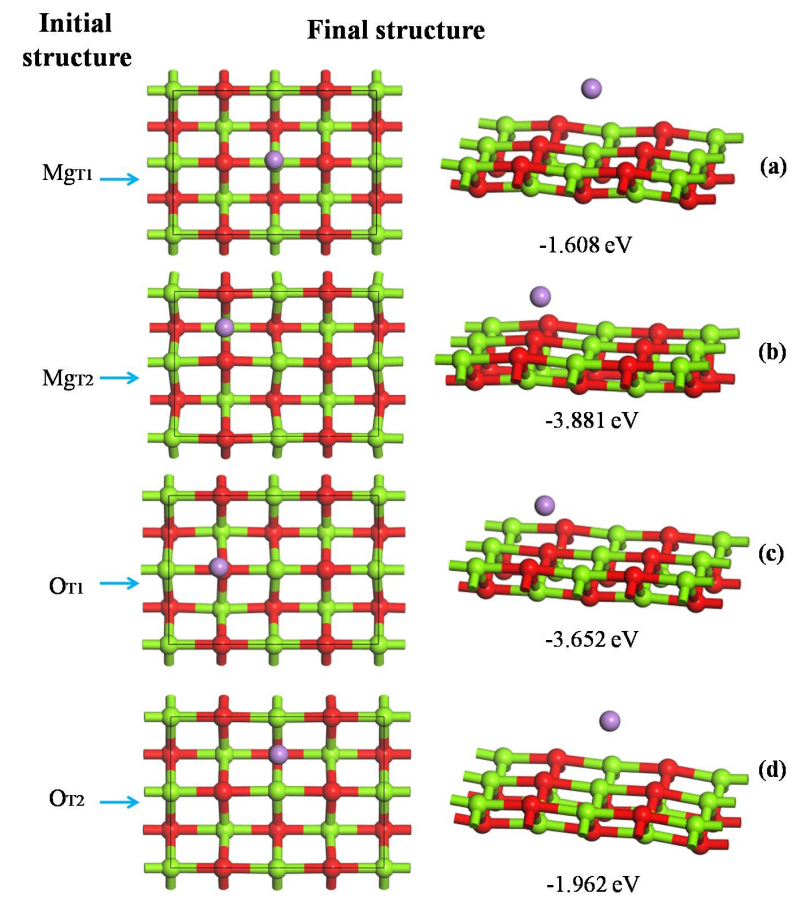

Fig. 10. The adsorption structures of As atoms at different adsorption sites.

\section{Conclusions}

In general, among the five oxides in fly ash, the As atom adsorbs most readily on the $\mathrm{Fe}_{2} \mathrm{O}_{3}$ and the optimal adsorption energy is $-13.860 \mathrm{eV}$. The adsorption ability of $\mathrm{Al}_{2} \mathrm{O}_{3}$ to As atom is the weakest, which in the range of $-2.295 \sim-2.704 \mathrm{eV}$. Therefore, the $\mathrm{Fe}_{2} \mathrm{O}_{3}$ in fly ash can be considered as the main active component to adsorb gaseous As. This paper proves the feasibility of using fly ash as the adsorbent to control As pollution preliminarily, and also provides some help for the subsequent experimental research.

\section{Acknowledgement}

This work was sponsored by National Key Research and Development Project of China (2018YFB0605103-4).

\section{References}

1. M.A. Gonzalez-Salazar, T. Kirsten, L. Prchlik, Renewable and Sustainable Energy Reviews, 82: 1497-1513 (2018)

2. B. Zheng, D. Tong, M. Li, F. Liu, C. Hong, G. Geng, H. Li, X. Li, L. Peng, J. Qi, L. Yan, Y. Zhang, H. Zhao, Y. Zheng, K. He, Q. Zhang, Atmospheric Chemistry and Physics, 18, 19: 14095-14111 (2018)

3. X. Zhou, J. Wu, Q. Li, T. Zeng, Z. Ji, P. He, W. Pan, X. Qi, C. Wang, P. Liang, Journal of Catalysis, 355: 26-39 (2017)

4. X. Qi, M. Gu, X. Zhu, J. Wu, H. Long, K. He, Q. $\mathrm{Wu}$, Chemical Engineering Journal, 285:11-19 (2016) 
5. P. He, X. Zhang, X. Peng, J. Wu, N. Chen, J. Ren, Fuel, 162: 211-214 (2015)

6. H. Liu, B. Jing, B. Fan, Y. Jin, Journal of Engineering Thermophysics, 35, 4 (2014)

7. Y. Fan, Y. Zhuo, Z. Zhu, W. Du, L. Li, J Phys Chem A, 121, 39: 7385-7392 (2017)

8. J. Huang, X. Li, X. Wang, X. Fang, H. Wang, X. Xu, Journal of $\mathrm{CO}_{2}$ Utilization, 33: 55-63 (2019) 